\title{
Taurine Transporter Gene Expression in Mononuclear Blood Cells of Type 1 Diabetes Patients
}

\author{
Zaleida Napoli, ${ }^{1}$ Giuseppe Seghieri, ${ }^{2,3}$ Loria Bianchi, ${ }^{1}$ Roberto Anichini, \\ Alessandra De Bellis, ${ }^{4}$ Ilaria Campesi, ${ }^{5}$ Ciriaco Carru, ${ }^{5}$ Stefano Occhioni, ${ }^{5}$ \\ Angelo Zinellu, ${ }^{5}$ and Flavia Franconi ${ }^{5}$ \\ ${ }^{1}$ Department of Clinical Chemistry, S. Jacopo Hospital, 51100 Pistoia, Italy \\ ${ }^{2}$ Agenzia Regionale Sanità, Toscana, Florence, Italy \\ ${ }^{3}$ Accademia Medica Pistoiese F. Pacini, 51100 Pistoia, Italy \\ ${ }^{4}$ Diabetes Unit, S. Jacopo Hospital, 51100 Pistoia, Italy \\ ${ }^{5}$ Department of Biomedical Sciences, University of Sassari, 07100 Sassari, Italy \\ Correspondence should be addressed to Giuseppe Seghieri; gseghier@tin.it
}

Received 5 November 2015; Revised 7 January 2016; Accepted 11 January 2016

Academic Editor: Ronald G. Tilton

Copyright (C) 2016 Zaleida Napoli et al. This is an open access article distributed under the Creative Commons Attribution License, which permits unrestricted use, distribution, and reproduction in any medium, provided the original work is properly cited.

\begin{abstract}
Background. Taurine transporter gene expression (RNA-TauT) has a role in retinal cell function and is modulated in vitro and in vivo by hyperglycemia and/or oxidative stress. This study was aimed at testing whether RNA-TauT gene expression is modified in blood mononuclear peripheral cells (MPCs) of type 1 diabetic patients, is related to plasma markers of oxidative stress or endothelial dysfunction, or, finally, is related to presence of retinopathy. Methods. RNA-TauT was measured in MPCs by real-time PCR-analysis in 35 type 1 diabetic patients and in 33 age- and sex-matched controls, additionally measuring plasma and cell taurine and markers of oxidative stress and endothelial dysfunction. Results. RNA-TauT, expressed as $2^{-\Delta \Delta \mathrm{Ct}}$, was significantly higher in MPCs of type 1 diabetic patients than in controls [median (interquartile range): 1.32(0.31) versus $1.00(0.15) ; P=0.01$ ]. In diabetic patients RNATauT was related to HbAlc $(r=0.42 ; P=0.01)$ and inversely to plasma homocysteine $(r=-0.39 ; P=0.02)$ being additionally significantly higher in MPCs of patients without retinopathy $[(n=22) ; 1.36(0.34)]$ compared to those with retinopathy $[(n=13)$; 1.16(0.20)], independently from HbA1c or diabetes duration. Conclusions. RNA-TauT gene expression is significantly upregulated in MPCs of type 1 diabetes patients and is related to HbAlc levels and inversely to plasma homocysteine. Finally, in diabetes patients, RNA-TauT upregulation seems to be blunted in patients with retinopathy independently of their metabolic control or longer diabetes duration.
\end{abstract}

\section{Introduction}

The sulfur amino acid taurine is the most abundant free amino acid in the human body and is involved in many fundamental biological functions such as antioxidation, osmoregulation, and $\mathrm{Ca}++$ transport regulation. It also has anti-inflammatory effects $[1,2]$. In humans, the main source of taurine is the diet, the rate of endogenous synthesis being relatively low.

Taurine has preventive effects against the incidence of diabetes, improving insulin sensitivity and secretion in animal models and in humans [3-5]. In addition, taurine plays an important role in retinal function, at least in animal models, as demonstrated by the dated observation about a close relationship between taurine deficiency and retinal degeneration in the cat [6]. This relationship assumes an ever greater significance in diabetes since dietary taurine supplementation prevents glial alterations in the retina of diabetic rats [7] and, consequently, ameliorates diabetic microangiopathy, including retinopathy [8-10].

Taurine is $10^{3}$-fold more concentrated in the intracellular space, due to the action of a specific sodium-dependent transporter (TauT). The latter is upregulated by several conditions, including hypertonicity, low extracellular taurine, 
and oxidative stress [11, 12], all of which are frequently found in diabetic patients [13-15]. In regard to hypertonicity, it is known that taurine is an osmolyte involved in cell volume regulation $[2,4]$ and hyperosmolality associated with diabetic hyperglycemia could trigger increased gene expression of TauT. It has moreover recently been shown that blood mononuclear peripheral cells (MPCs) obtained from type 2 diabetic patients overexpress the TauT gene, and this overexpression seems to be blunted in the presence of retinopathy [16].

The aim of this study was to test whether TauT mRNA gene expression is also modified in MPCs of type 1 diabetic patients, who are, differently from type 2 diabetic patients, characterized by a younger age, longer duration of disease, and requirement of insulin therapy since the onset of disease. Further objectives of this study were investigating whether TauT mRNA expression is modulated by plasma levels of oxidative stress or endothelial dysfunction markers or, finally, whether it is related to the presence of retinopathy.

\section{Materials and Methods}

2.1. Patients and Controls. Type 1 diabetic patients were recruited from among the diabetic subjects who consecutively attend the Diabetes Outpatient Clinic of the Pistoia Hospital. Retinopathy was ascertained by retinal fluorescein angiography as previously described [17].

Renal pathology was investigated by estimation of urinary albumin to creatinine ratio using spot urine samples, and all patients were in the normoalbuminuric range except for one.

Macroangiopathy, ascertained by patients' previous medical history and clinical-instrumental criteria, was excluded in all cases but two. Clinical evidence of peripheral neuropathy was excluded in all cases.

Age- and sex-matched controls were recruited from among hospital personnel or their relatives. Neither patients nor controls took extra vitamins or drugs potentially known to modify both taurine and its cell transporter.

This study was approved by the Ethics Committee of the Pistoia Hospital and all subjects gave their written informed consent prior to their inclusion in the study.

2.2. Biochemical Assays. We measured fasting plasma glucose and glycated hemoglobin (HbAlc) (resp., by the glucose oxidase method and by HPLC, Bio-Rad Laboratories, USA) in both patients and controls. Plasma levels of malonyldialdehyde (MDA) were measured spectrophotometrically by the thiobarbituric method as previously described [18]. Carbonylated proteins were quantified spectrophotometrically after protein precipitation with $10 \%$ TCA as described by Fagan et al. [19]. Plasma levels of asymmetric dimethylarginine (ADMA), symmetric dimethylarginine (SDMA), and arginine were measured by field-amplified sample injection capillary electrophoresis as previously reported [20] and plasma homocysteine by fluorescence polarization immunoassay (FPIA, Abbott, Italy). Serum and cell taurine, expressed as $\mathrm{nmol} / 10^{6}$ cells, were measured by capillary electrophoresis with laser-induced fluorescence detection [21, 22]. Each sample was assayed in duplicate.
2.3. RNA-Taurine Transporter Gene Expression. Blood mononuclear peripheral cells (MPCs, lymphocytes and monocytes) were extracted from $9 \mathrm{~mL}$ of whole blood in each subject by Accuspin System-Histopaque-1077 (Sigma-Aldrich, Italy) and separated into two aliquots: one aliquot was resuspended in $200 \mu \mathrm{L}$ of RNAlater RNA stabilization Reagent (Qiagen, UK) for RNA extraction, and one aliquot was resuspended in $200 \mu \mathrm{L}$ of PBS solution for intracellular content determinations. Each sample contained a median count of $2.59 *$ $10^{6}$ [interquartile range: $0.8 * 10^{6}$ ] cells $/ \mathrm{mL}$, comprised of $2.09 * 10^{6}$ [interquartile range: $0.7 * 10^{6}$ ] lymphocytes $/ \mathrm{mL}$ and $0.5 * 10^{6}$ [interquartile range: $0.12 * 10^{6}$ ] monocytes $/ \mathrm{mL}$. The average amount of total cells obtained from extraction in each aliquot was $4.1 * 10^{6}\left(19.4 * 10^{3}\right.$ cells $/ \mu \mathrm{L}$, interquartile range: $18.3 * 10^{3}$ cells $/ \mu \mathrm{L}$ ), with an average cellular extraction yield of $43.37 \% \pm 6.68 \%$ (95\% IC; from a minimum of $0.55 \%$ to a maximum of $96.4 \%$ ). TauT mRNA was quantified by real-time (RT) PCR (Rotorgene 6000, Qiagen, UK), as previously described [16], using hypoxanthine-guanine phosphoribosyltransferase (HPRT) as house-keeping gene. Primers' sequence for TauT (SLC6A6; gene accession number: NM_001134367) was 5'-TATCTGTATCCTGACATCACCCG-3' (forward) and 5' -CCCAGGCAGATGGCATAAGAG-3' (reverse), while for HPRT it (gene accession number: NM_000194) was 5'-GAAGGTGAAGGTCGGAGT-3' (forward) and $5^{\prime}$-GAAGATGGTGATGGGATTTA-3' (reverse) [23].

Relative quantification was performed using the comparative cycle threshold $(\mathrm{Ct})$ method after determining the $\mathrm{Ct}$ values for the reference (HPRT) and target gene (TauT) in each sample, according to the $2^{-\Delta \Delta C t}$ method [24]. To assess whether two amplifications have the same efficiency (required condition for $2^{-\Delta \Delta \mathrm{Ct}}$ method), ten standard curves were generated by reverse transcription of Human Reference Total RNA (Agilent Technologies, USA) and amplification of scalar 1:5 dilutions of cDNA. Standard curves showed efficiencies between $0.79 \pm 0.02$ (IC 95\%, CV $=4.15 \%$ ) for HPRT and $0.76 \pm 0.03$ (IC 95\%, CV $=5.36 \%$ ) for TauT, with a linearity range between 100 and $0.16 \mu \mathrm{g} / \mathrm{mL}$ of total RNA.

2.4. Statistical Methods. Comparisons among groups, often including nonnormally distributed elements, were analyzed using the Wilcoxon-Mann-Whitney test and relations among variables were tested by Spearman's correlation coefficients. Nonnormally distributed variables were expressed as median [interquartile ranges]. The significance of $P$ value was set at $<0.05$. All statistical analyses were carried out by means of SAS software for Windows, version 9.3 (SAS Institute Inc., Cary, NC, USA).

\section{Results}

Controls and diabetic patients were matched for age, sex, and body mass index (BMI). Fasting plasma glucose and HbAlc were significantly higher in diabetic patients. The TauT mRNA gene expression in MPCs was significantly higher, by about $32 \%$, in diabetic patients, compared to healthy volunteers (Table 1, Figure 1). 
TABLE 1: Main characteristics of diabetic patients and control subjects.

\begin{tabular}{|c|c|c|c|}
\hline & Controls & Type 1 diabetic patients & $P$ \\
\hline Number & 33 & 35 & \\
\hline Age (yr) & $41 \pm 11$ & $44 \pm 12$ & NS \\
\hline $\operatorname{Sex}(M / F)$ & $12 / 21$ & $18 / 17$ & NS \\
\hline $\mathrm{BMI}\left(\mathrm{Kg} / \mathrm{m}^{2}\right)$ & $23.9 \pm 3.3$ & $25.2 \pm 4.1$ & NS \\
\hline Duration of diabetes (yr) & - & $23.13 \pm 9.44$ & - \\
\hline Plasma glucose $(\mathrm{mmol} / \mathrm{L})$ & $5.32 \pm 0.48$ & $8.29 \pm 3.27$ & 0.0001 \\
\hline $\mathrm{HbAlc}(\%, \mathrm{mmol} / \mathrm{mol})$ & $5.38 \pm 0.38,34.64 \pm 4.15$ & $7.88 \pm 1.07,62.71 \pm 11.70$ & 0.0001 \\
\hline Plasma taurine $(\mu \mathrm{mol} / \mathrm{L})$ & $51.05(19.30)$ & $47.39(23.46)$ & NS \\
\hline Intracellular taurine ( $\mathrm{nmol} / 10^{6}$ cells) & $38.33(26.9)$ & $54.19(36.87)$ & NS \\
\hline Plasma arginine $(\mu \mathrm{mol} / \mathrm{L})$ & $90.88(19.49)$ & $83.71(23.41)$ & NS \\
\hline Plasma homocysteine $(\mu \mathrm{mol} / \mathrm{L})$ & $11.4(3.3)$ & $11.1(6.1)$ & NS \\
\hline Asymmetric dimethylarginine $(\mu \mathrm{mol} / \mathrm{L})$ & $0.56(0.22)$ & $0.56(0.13)$ & NS \\
\hline Symmetric dimethylarginine $(\mu \mathrm{mol} / \mathrm{L})$ & $0.51(0.28)$ & $0.51(0.14)$ & NS \\
\hline Plasma malonyldialdehyde $(\mu \mathrm{mol} / \mathrm{L})$ & $3.55(2.14)$ & $4.47(1.68)$ & NS \\
\hline Intracellular carbonyls ( $\mathrm{nmol} / \mathrm{mg}$ ) & $1.37(0.82)$ & $1.30(0.56)$ & NS \\
\hline Lymphocytes $\left(10^{6}\right.$ cells $\left./ \mathrm{mL}\right)$ & $2.60(0.86)$ & $2.35(0.79)$ & NS \\
\hline Monocytes $\left(10^{6}\right.$ cells $\left./ \mathrm{mL}\right)$ & $0.50(0.16)$ & $0.45(0.19)$ & NS \\
\hline TauT mRNA gene expression $\left(2^{-\Delta \Delta C t}\right)$ & $1.00(0.15)$ & $1.32(0.31)$ & 0.0001 \\
\hline Urinary albumin/creatinine $(\mu \mathrm{g} / \mathrm{mg})$ & $5.277(7.014)$ & $5.601(6.821)$ & NS \\
\hline
\end{tabular}

Data are shown as median (interquartile range) or mean \pm SD.

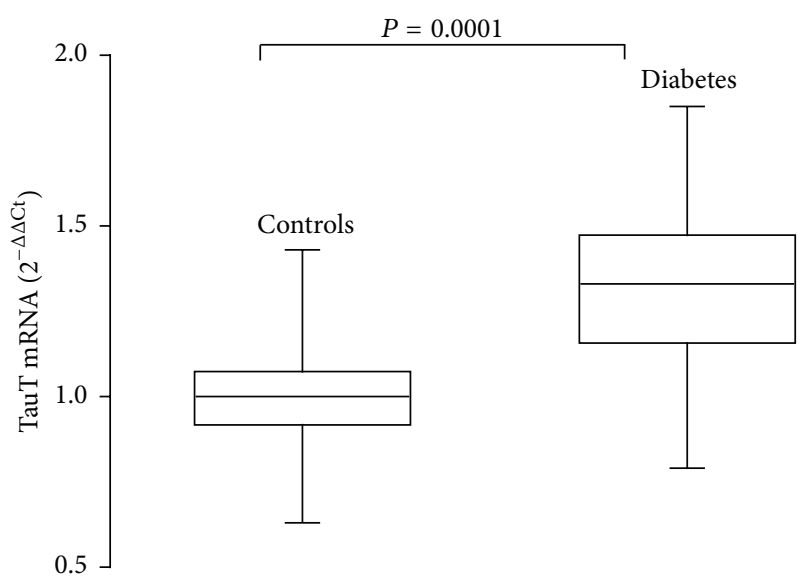

FIgURE 1: Box and whisker plots of TauT mRNA gene expression in mononuclear peripheral blood cells of type 1 diabetes patients and of controls.

Among controls no correlation was observed between TauT mRNA gene expression and HbAlc, fasting plasma glucose, homocysteine, malonyldialdehyde, carbonyl groups, ADMA, and SDMA (Table 2). TauT mRNA was not significantly related to plasma- or intracellular taurine (Table 2, Figure 2). In diabetic patients, the TauT mRNA gene was positively related to $\mathrm{HbAlc}(r=0.42 ; P=0.01$, Figure 3(a)), whereas it was not related to fasting plasma glucose $(r=0.22$; $P=$ NS, Table 2). Duration of diabetes was inversely related to TauT mRNA gene expression, even if not significantly $(r=-0.26 ; P=0.06)$. Finally, TauT mRNA gene expression was inversely related to plasma homocysteine $(r=-0.39$; $P=0.02$ ); (Table 2, Figure 3(b)).
All diabetic patients were on insulin therapy and plasma insulin levels, evaluated together with TauT mRNA, were not significantly related to each other $(r=-0.058 ; P=\mathrm{NS})$.

Patients with retinopathy had a longer duration of disease and a significantly lower TauT mRNA gene expression than the subjects without retinopathy, while no significant difference was observed for any other studied plasma marker between these two groups (Table 3, Figure 4). In addition, higher TauT mRNA gene expression remained significantly related to absence of retinopathy, after adjusting for HbAlc and disease duration by a multiple regression analysis $(P=$ $0.01)$.

Finally, no significant difference was found between plasma or cell taurine concentration of retinopathic versus nonretinopathic patients, although the intracellular level tended to be higher in the latter (Table 3). Again, in the whole group of diabetes patients, after a multivariate model with HbAlc and length of disease as covariates, presence of retinopathy was independently and significantly associated with a decrease in TauT mRNA $(P=0.02)$.

\section{Discussion}

This study provides evidence that type 1 diabetes patients have a significant increase (by about $30 \%$ ) in TauT mRNA gene expression in MPCs, when compared with age- and sexmatched control healthy subjects, and that such expression is directly related to HbAlc, suggesting the hypothesis that diabetes, "in vivo," may be able to chronically induce cell TauT mRNA gene expression, hypothetically as a defense measure, to improve cell homeostasis against the exposure to chronically higher glucose levels. These data observed "in 
TABLE 2: Correlation coefficients between TauT mRNA expression in MPCs of controls or type 1 diabetic patients and plasma glucose and markers of endothelial function or oxidative stress.

\begin{tabular}{lcccc}
\hline & & Controls & & \multicolumn{2}{c}{ Type 1 diabetic patients } \\
& $r$ & $P$ & 0.22 & NS \\
Plasma glucose & 0.27 & NS & -0.29 & NS \\
Plasma taurine* $^{*}$ & 0.25 & NS & -0.03 & NS \\
Cell taurine* & 0.24 & NS & -0.23 & NS \\
Plasma arginine* & -0.11 & NS & -0.39 & 0.02 \\
Plasma homocysteine* $^{*}$ & -0.14 & NS & NS & NS \\
Asymmetric dimethylarginine* $_{\text {Symmetric dimethylarginine* }}^{*}$ & -0.14 & NS & 0.30 & NS \\
Plasma malonyldialdehyde* $_{\text {Cellular carbonyls* }}^{*}$ & -0.04 & NS & -0.23 & -0.06 \\
\hline
\end{tabular}

${ }^{*} \log$ transformed.

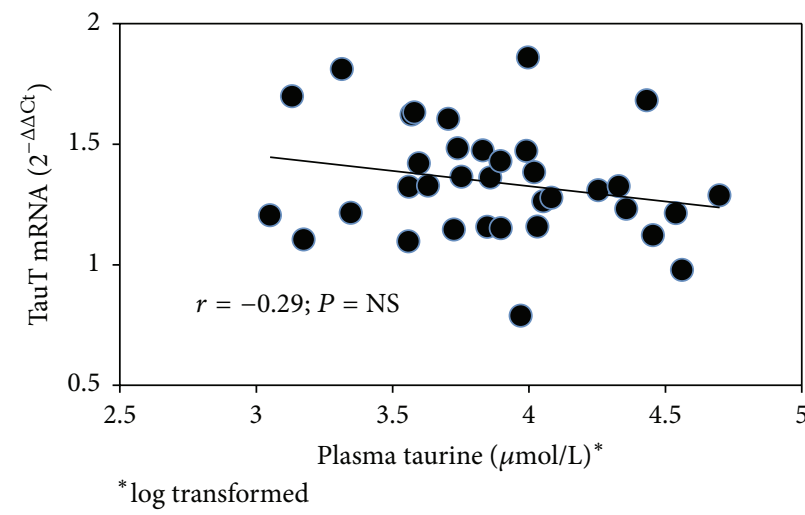

(a)

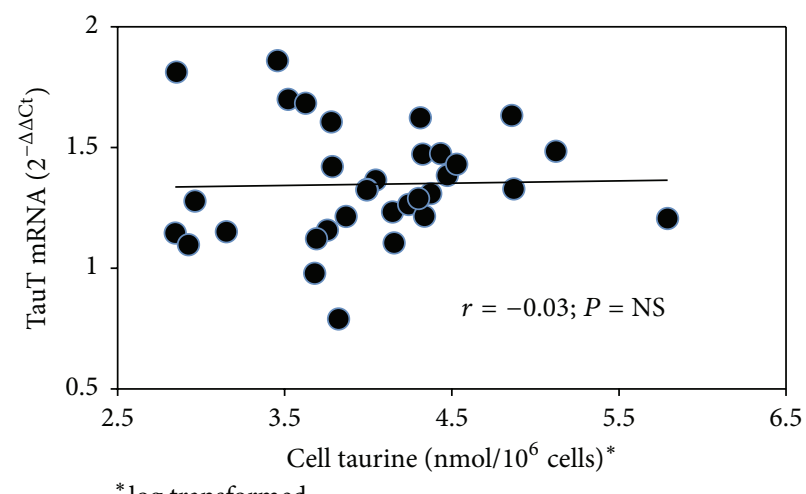

${ }^{*} \log$ transformed

(b)

FIgURE 2: Relation between TauT mRNA gene expression and plasma (a), or cell taurine (b), in MPCs from type 1 diabetic patients.

vivo" seem to be quite different from the findings obtained in experimental models "in vitro" where acute exposure to hyperglycemia and oxidative stress downregulate TauT mRNA gene expression in some cellular types [25-28].

In addition, a possible action of prevailing insulin levels on TauT cell gene expression was excluded by the absence of any relationship between plasma insulin concentrations and TauT gene expression in diabetic patients.

At variance with previous observations [29], no significant differences were observed between plasma or cell taurine concentrations from type 1 diabetic patients compared to control subjects. It is well known, however, that plasma levels of taurine are highly dependent on exogenous dietetic sources [4], and this may be the reason for this discrepancy. Concerning this point, since low extracellular levels of taurine trigger an increase in TauT cell expression and action in vitro $[11,12]$, having found unmodified plasma taurine levels between diabetic patients and controls could, at least partially, explain why taurine cell content was not significantly higher in diabetic individuals.

Plasma MDA, mirroring lipid peroxidation, was higher, even if not significantly, in patients with type 1 diabetes, and, in this case, it is not possible to speculate whether lipid peroxidation may contribute to modify TauT mRNA gene expression in MPCs. While no significant relationship was found between TauT mRNA gene expression and any single plasma marker of oxidative stress, TauT mRNA gene expression was inversely linked with plasma homocysteine. Interestingly this correlation was found only in the group of patients with diabetes, even if plasma levels of homocysteine were similar in patients with diabetes and in healthy controls, suggesting that plasma concentration of homocysteine could play a role in the regulation of TauT mRNA gene expression in diabetic subjects. In addition, even if the design of the study does not permit mechanistic conclusions, the inverse relationship between plasma homocysteine and TauT mRNA gene expression suggests that an increase in extracellular levels of homocysteine could be related to TauT mRNA downregulation. This is in agreement with the observation that homocysteine impairs active taurine transmembrane transport, as observed several years ago in vitro in synaptosomes, cultured neurons, and astrocytes [30]. More recently, just to reaffirm this finding in another cell model, it has been demonstrated that homocysteine inhibits taurine uptake in vitro from myocardial mitochondria of rats in a concentration-dependent manner [31]. 
TABLE 3: TauT mRNA cell expression and plasma markers of oxidative stress or endothelial function in controls and in type 1 diabetic patients with or without retinopathy.

\begin{tabular}{|c|c|c|c|}
\hline & No retinopathy & Retinopathy & $P$ \\
\hline Number & 22 & 13 & \\
\hline Duration (yr) & $17.50 \pm 10.63$ & $26.07 \pm 9.37$ & 0.02 \\
\hline $\mathrm{HbAlc}(\%, \mathrm{mmol} / \mathrm{mol})$ & $7.77 \pm 1.09,61.50 \pm 11.98$ & $8.07 \pm 1.04,64.77 \pm 11.38$ & NS \\
\hline Plasma taurine $(\mu \mathrm{mol} / \mathrm{L})$ & $46.49(23.79)$ & $49.23(18.58)$ & NS \\
\hline Intracellular taurine (nmol/106 cells) & $63.19(32.73)$ & $43.34(42.06)$ & NS \\
\hline Plasma arginine $(\mu \mathrm{mol} / \mathrm{L})$ & $84.04(16.72)$ & $82.95(44.71)$ & NS \\
\hline Plasma homocysteine $(\mu \mathrm{mol} / \mathrm{L})$ & $10.90(4.97)$ & $13.1(5.20)$ & NS \\
\hline Asymmetric dimethylarginine $(\mu \mathrm{mol} / \mathrm{L})$ & $0.57(0.13)$ & $0.56(0.10)$ & NS \\
\hline Symmetric dimethylarginine $(\mu \mathrm{mol} / \mathrm{L})$ & $0.51(0.15)$ & $0.53(0.22)$ & NS \\
\hline Malonyldialdehyde $(\mu \mathrm{mol} / \mathrm{L})$ & $4.27(1.71)$ & $4.49(1.83)$ & NS \\
\hline Cellular carbonyls (nmol/mg) & $1.22(0.62)$ & $1.50(0.49)$ & NS \\
\hline TauT mRNA gene expression $\left(2^{-\Delta \Delta \mathrm{Ct}}\right)$ & $1.36(0.34)$ & $1.16(0.20)$ & 0.02 \\
\hline
\end{tabular}

Data are shown as median (interquartile range) or mean \pm SD.

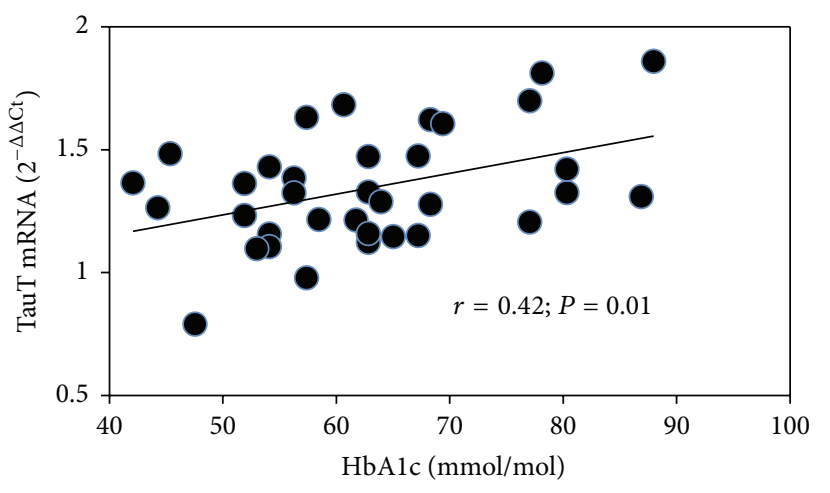

${ }^{*} \log$ transformed

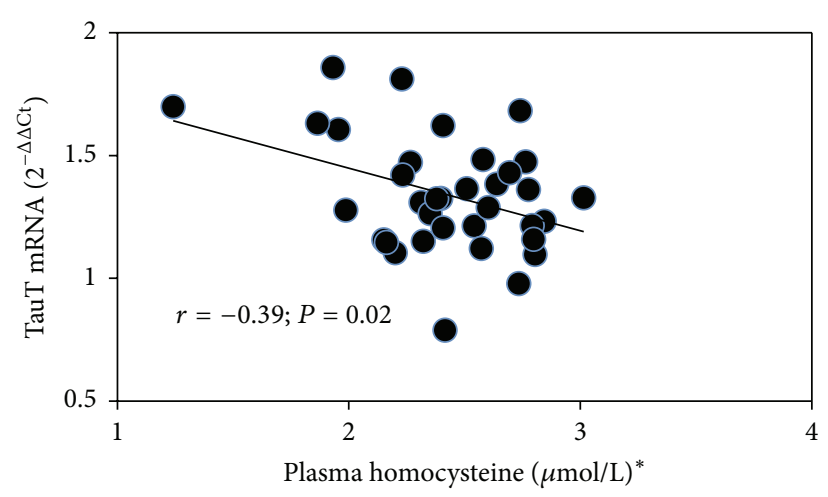

${ }^{*} \log$ transformed

(a)

(b)

Figure 3: Relation between TauT mRNA gene expression and HbAlc (a), or plasma homocysteine (b), in MPCs from type 1 diabetic patients.

Furthermore, TauT-mediated cell taurine influx might be modulated by intracellular synthesis of taurine originating from the transsulfuration pathway of homocysteine to cysteine and then to taurine [32], while, conversely, taurine supplementation might increase homocysteine metabolism, as happens in mice with cystathionine $\beta$-synthase-deficient homocystinuria [33].

In conclusion levels of homocysteine could be crucial in modifying cell TauT gene expression in patients with diabetes and differences in plasma levels of this amino acid as well as of taurine could determine differences in TauT gene expression as, for instance, noted between patients with type 1 and type 2 diabetes.

In agreement with what we have observed in type 2 diabetes [16], a further interesting point of this study is that type 1 diabetic patients without retinopathy, as compared to diabetic patients with retinopathy, are characterized by higher TauT mRNA gene expression in MPCs. TauT is involved in the active transport of taurine to the retinal pigment epithelial apical membrane [26] and a high concentration of taurine is essential for maintaining the structural and functional integrity of the retina [6]. This reduction in TauT mRNA gene expression in presence of retinopathy could thus represent an impairment in cell defense against chronic hyperglycemia, unanimously considered a main cause in the pathogenesis of diabetic retinopathy. Once again, however, what we have observed "in vivo" in diabetic patients appears to be different from TauT gene downregulation after the acute challenge of retinal epithelial and glial cells to high glucose levels "in vitro" $[26,34]$. Our hypothesis is, however, reinforced by the fact that, interestingly, in animal models (diabetic rats), contrary to what happens in acute conditions, chronic exposure to high glucose levels seems to enhance active taurine uptake in retinal pigment epithelial cells, indirectly suggesting that diabetes is able to chronically stimulate "in vivo" TauT expression in these cells [35]. All this permits recalling that exposing the taurine-TauT system to higher glucose concentrations "in vitro" is completely different from testing it in a clinical condition such as diabetes, which is characterized by a much longer exposure time to extracellular 


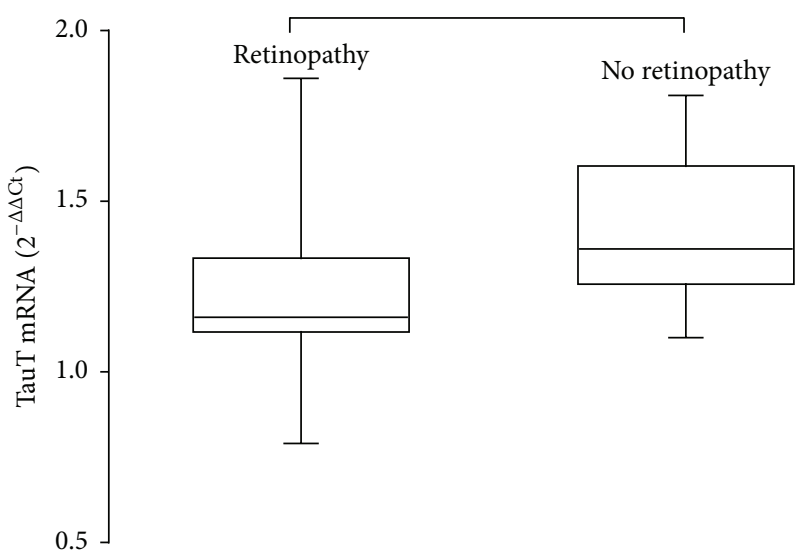

FIgURE 4: Box and whisker plots of TauT mRNA gene expression in mononuclear peripheral blood cells of type 1 diabetes with or without retinopathy.

high glucose levels and moreover includes a more complex biochemical milieu done by amino acids, lipids, or oxidative stress-associated metabolites.

Finally, no difference was found in TauT mRNA gene expression among patients with more advanced grades of retinopathy, probably due to the low number $(n=2)$ of patients with proliferative retinopathy.

\section{Strengths and Limitations of the Study}

A major strength of this study is represented by the further evidence that TauT gene expression is significantly upregulated in MPCs of patients with diabetes and is directly related to HbAlc, thus suggesting being a sort of response to the chronic impairment of plasma glucose control in diabetes. The study presents, however, some limitations: first, it is a cross-sectional study and does not permit evaluating any time-course of TauT mRNA expression and duration of disease, especially in relation to development of diabetes complications such as retinopathy. Secondly, the design of the study does not allow investigating whether TauT gene expression is modified at different target cell models.

\section{Conclusions}

In conclusion, this study highlights that TauT mRNA gene expression is upregulated in MPCs in type 1 diabetic patients, although to a much lesser extent than what we observed in type 2 diabetes [16]. We are not able to give explanation of the difference between the two types of diabetes: we can only exclude the effect of therapy or of a different metabolic control (which was similar to that observed in the study concerning type 2 diabetic patients). Probably, as highlighted above, a longer duration of diabetes, the different effect of plasma taurine concentrations (lower in the previous study concerning patients with type 2 diabetes), or a possible difference in plasma homocysteine levels might, at least partially, altogether explain such a difference. In addition, we can confirm that TauT mRNA expression in MPCs is positively related to metabolic control (HbAlc) and, finally, it seems to be inversely related to plasma homocysteine.

Even more interesting, however, is the fact that TauT mRNA expression is lower in patients with retinopathy, confirming what we observed in type 2 diabetes.

Finally, if our analyses excluded a significant relation between TauT $m R N A$ gene expression and diabetes duration $(r=-0.26 ; P=0.06)$, further studies are needed to confirm the hypothesis that a way by which prolonged duration of hyperglycemia may induce the appearance of retinopathy can be also due to the progressive fading in upregulation of TauT gene expression.

\section{Conflict of Interests}

The authors confirm that there is no conflict of interests.

\section{Authors' Contribution}

Zaleida Napoli, Giuseppe Seghieri, Loria Bianchi, and Flavia Franconi conceived and designed the study; Zaleida Napoli, Loria Bianchi, and Giuseppe Seghieri analyzed the data; Ilaria Campesi, Angelo Zinellu, Ciriaco Carru, and Stefano Occhioni gave a substantial contribution in performing the biochemical evaluation of oxidative and endothelial dysfunction markers; Giuseppe Seghieri wrote the paper; Roberto Anichini and Alessandra De Bellis recruited patients and discussed and edited the paper. Giuseppe Seghieri is, moreover, the guarantor of this paper, had full access to all the data in the study, and takes the responsibility for the integrity of data and accuracy of data analysis.

\section{Acknowledgments}

This work was supported by a grant from the Fondazione Cassa di Risparmio di Pistoia e Pescia, Pistoia, Italy, and from the Accademia Medica Pistoiese "Filippo Pacini", Pistoia, Italy. The authors thank Mary Forrest for editing the paper. The authors acknowledge the precious technical help of Angela Berti and Swan Donati.

\section{References}

[1] R. J. Huxtable, "Physiological actions of taurine," Physiological Reviews, vol. 72, no. 1, pp. 101-163, 1992.

[2] S. W. Schaffer, T. Ito, and J. Azuma, "Clinical significance of taurine," Amino Acids, vol. 46, no. 1, pp. 1-5, 2014.

[3] M. Imae, T. Asano, and S. Murakami, "Potential role of taurine in the prevention of diabetes and metabolic syndrome," Amino Acids, vol. 46, no. 1, pp. 81-88, 2014.

[4] H. Ripps and W. Shen, "Review: taurine: a "very essential" amino acid," Molecular Vision, vol. 18, pp. 2673-2686, 2012.

[5] T. Ito, S. W. Schaffer, and J. Azuma, "The potential usefulness of taurine on diabetes mellitus and its complications," Amino Acids, vol. 42, no. 5, pp. 1529-1539, 2012.

[6] K. C. Hayes, R. E. Carey, and S. Y. Schmidt, "Retinal degeneration associated with taurine deficiency in the cat," Science, vol. 188, no. 4191, pp. 949-951, 1975. 
[7] K. Zeng, H. Xu, M. Mi et al., "Effects of taurine on glial cells apoptosis and taurine transporter expression in retina under diabetic conditions," Neurochemical Research, vol. 35, no. 10, pp. 1566-1574, 2010.

[8] S. H. Hansen, "The role of taurine in diabetes and the development of diabetic complications," Diabetes/Metabolism Research and Reviews, vol. 17, no. 5, pp. 330-346, 2001.

[9] M. A. S. Di Leo, S. A. Santini, S. Cercone et al., "Chronic taurine supplementation ameliorates oxidative stress and $\mathrm{Na}^{+}$ $\mathrm{K}^{+}$ATPase impairment in the retina of diabetic rats," Amino Acids, vol. 23, no. 4, pp. 401-406, 2002.

[10] M. A. S. Di Leo, G. Ghirlanda, N. Gentiloni Silveri, B. Giardina, F. Franconi, and S. A. Santini, "Potential therapeutic effect of antioxidants in experimental diabetic retina: a comparison between chronic taurine and vitamin E plus selenium supplementations," Free Radical Research, vol. 37, no. 3, pp. 323-330, 2003.

[11] M. L. Tappaz, "Taurine biosynthetic enzymes and taurine transporter: molecular identification and regulations," Neurochemical Research, vol. 29, no. 1, pp. 83-96, 2004.

[12] X. Han, A. B. Patters, D. P. Jones, I. Zelikovic, and R. W. Chesney, "The taurine transporter: mechanisms of regulation," Acta Physiologica, vol. 187, no. 1-2, pp. 61-73, 2006.

[13] F. Franconi, M. Miceli, A. Fazzini et al., "Taurine and diabetes. Humans and experimental models," in Taurine 2, vol. 403 of Advances in Experimental Medicine and Biology, pp. 579-582, Springer, New York, NY, USA, 1996.

[14] F. Franconi, A. Loizzo, G. Ghirlanda, and G. Seghieri, "Taurine supplementation and diabetes mellitus," Current Opinion in Clinical Nutrition and Metabolic Care, vol. 9, no. 1, pp. 32-36, 2006.

[15] J. W. Baynes and S. R. Thorpe, "Role of oxidative stress in diabetic complications: a new perspective on an old paradigm," Diabetes, vol. 48, no. 1, pp. 1-9, 1999.

[16] L. Bianchi, R. Lari, R. Anichini et al., "Taurine transporter gene expression in peripheral mononuclear blood cells of type 2 diabetic patients," Amino Acids, vol. 42, no. 6, pp. 2267-2274, 2012.

[17] P. Di Simplicio, L. A. De Giorgio, E. Cardaioli et al., "Glutathione, glutathione utitizing enzymes and thioltransferase in platetets of insulin-dependent diabetic patients: relation with platelet aggregation and with microangiopatic complications," European Journal of Clinical Investigation, vol. 25, no. 9, pp. 665669, 1995.

[18] I. Campesi, A. Galistu, C. Carru, F. Franconi, M. Fois, and A. Zinellu, "Glutamyl cycle in the rat liver appears to be sex-gender specific," Experimental and Toxicologic Pathology, vol. 65, no. 5, pp. 585-589, 2013.

[19] J. M. Fagan, B. G. Sleczka, and I. Sohar, "Quantitation of oxidative damage to tissue proteins," International Journal of Biochemistry and Cell Biology, vol. 31, no. 7, pp. 751-757, 1999.

[20] A. Zinellu, S. Sotgia, M. F. Usai, G. Pintus, L. Deiana, and C. Carru, "Improved method for plasma ADMA, SDMA, and arginine quantification by field-amplified sample injection capillary electrophoresis UV detection," Analytical and Bioanalytical Chemistry, vol. 399, no. 5, pp. 1815-1821, 2011.

[21] A. Zinellu, S. Sotgia, S. Bastianina et al., "Taurine determination by capillary electrophoresis with laser-induced fluorescence detection: from clinical field to quality food applications," Amino Acids, vol. 36, no. 1, pp. 35-41, 2009.
[22] A. Zinellu, S. Sotgia, E. Pisanu et al., "Quantification of neurotransmitter amino acids by capillary electrophoresis laserinduced fluorescence detection in biological fluids," Analytical and Bioanalytical Chemistry, vol. 398, no. 5, pp. 1973-1978, 2010.

[23] C. M. H. Anderson, A. Howard, J. R. F. Walters, V. Ganapathy, and D. T. Thwaites, "Taurine uptake across the human intestinal brush-border membrane is via two transporters: $\mathrm{H}^{+}$coupled PAT1 (SLC36A1) and $\mathrm{Na}^{+}$- and $\mathrm{Cl}^{-}$-dependent TauT (SLC6A6)," Journal of Physiology, vol. 587, no. 4, pp. 731-744, 2009.

[24] K. J. Livak and T. D. Schmittgen, "Analysis of relative gene expression data using real-time quantitative PCR and the $2^{-\triangle \triangle \mathrm{Ct}}$ method," Methods, vol. 25, no. 4, pp. 402-408, 2001.

[25] Y. R. Shi, L. Gao, S. H. Wang et al., "Inhibition of taurine transport by high concentration of glucose in cultured rat cardiomyocytes," Metabolism: Clinical and Experimental, vol. 52, no. 7, pp. 827-833, 2003.

[26] M. J. Stevens, Y. Hosaka, J. A. Masterson, S. M. Jones, T. P. Thomas, and D. D. Larkin, "Downregulation of the human taurine transporter by glucose in cultured retinal pigment epithelial cells," American Journal of Physiology - Endocrinology and Metabolism, vol. 277, no. 4, pp. E760-E771, 1999.

[27] E. Nakashima, R. Pop-Busui, R. Towns et al., "Regulation of the human taurine transporter by oxidative stress in retinal pigment epithelial cells stably transformed to overexpress aldose reductase," Antioxidants and Redox Signaling, vol. 7, no. 11-12, pp. 1530-1542, 2005.

[28] T. Askwith, W. Zeng, M. C. Eggo, and M. J. Stevens, "Oxidative stress and dysregulation of the taurine transporter in high-glucose-exposed human Schwann cells: implications for pathogenesis of diabetic neuropathy," The American Journal of Physiology-Endocrinology and Metabolism, vol. 297, no. 3, pp. E620-E628, 2009.

[29] F. Franconi, F. Bennardini, A. Mattana et al., "Plasma and platelet taurine are reduced in subjects with insulin-dependent diabetes mellitus: effects of taurine supplementation," The American Journal of Clinical Nutrition, vol. 61, no. 5, pp. 11151119, 1995.

[30] I. C. Allen, A. Schousboe, and R. Griffiths, "Effect of 1homocysteine and derivatives on the high-affinity uptake of taurine and GABA into synaptosomes and cultured neurons and astrocytes," Neurochemical Research, vol. 11, no. 11, pp. 14871496, 1986.

[31] L. Chang, J. Xu, F. Yu, J. Zhao, X. Tang, and C. Tang, “Taurine protected myocardial mitochondria injury induced by hyperhomocysteinemia in rats," Amino Acids, vol. 27, no. 1, pp. 37-48, 2004.

[32] J. T. Brosnan and M. E. Brosnan, "The sulfur-containing amino acids: an overview," Journal of Nutrition, vol. 136, no. 6, pp. 1636S-1640S, 2006.

[33] H. Jiang, S. P. Stabler, R. H. Allen, S. H. Abman, and K. N. Maclean, "Altered hepatic sulfur metabolism in cystathionine $\beta$-synthase-deficient homocystinuria: regulatory role of taurine on competing cysteine oxidation pathways," The FASEB Journal, vol. 28, no. 9, pp. 4044-4054, 2014.

[34] K. Zeng, H. Xu, M. Mi et al., "Dietary taurine supplementation prevents glial alterations in retina of diabetic rats," Neurochemical Research, vol. 34, no. 2, pp. 244-254, 2009.

[35] C. Vilchis and R. Salceda, "Effect of diabetes on levels and uptake of putative amino acid neurotransmitters in rat retina and retinal pigment epithelium," Neurochemical Research, vol. 21, no. 10, pp. 1167-1171, 1996. 


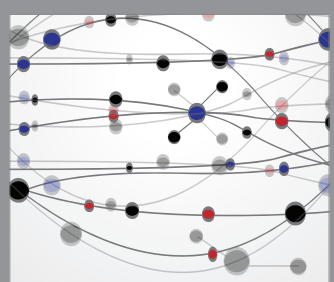

The Scientific World Journal
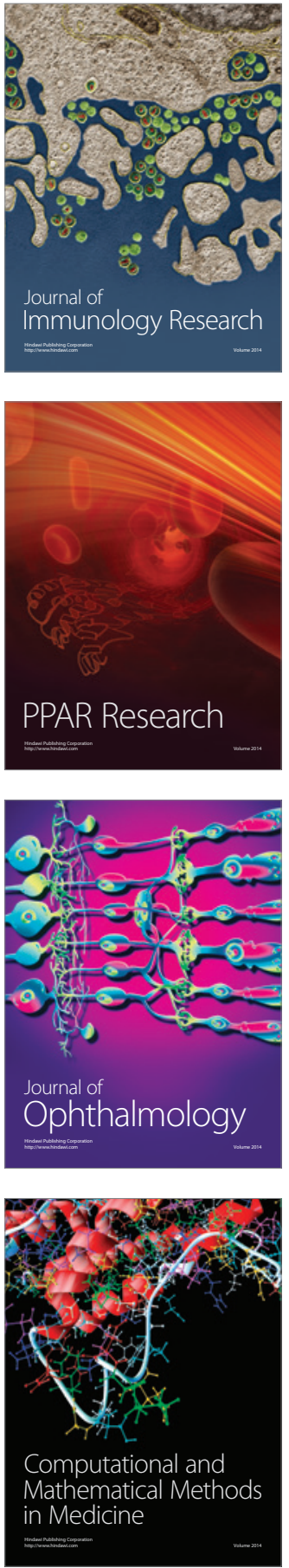

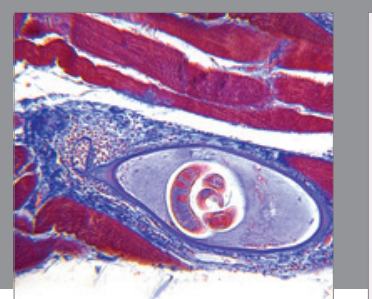

Gastroenterology Research and Practice

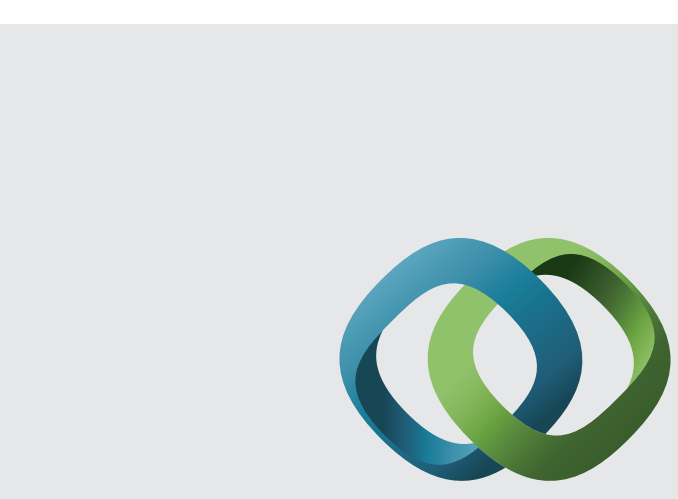

\section{Hindawi}

Submit your manuscripts at

http://www.hindawi.com
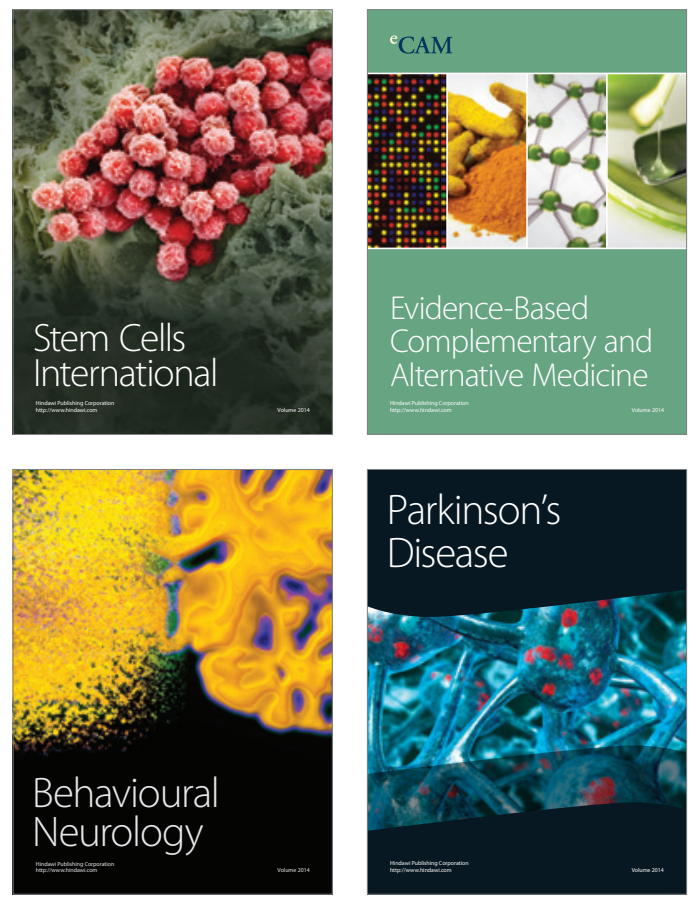
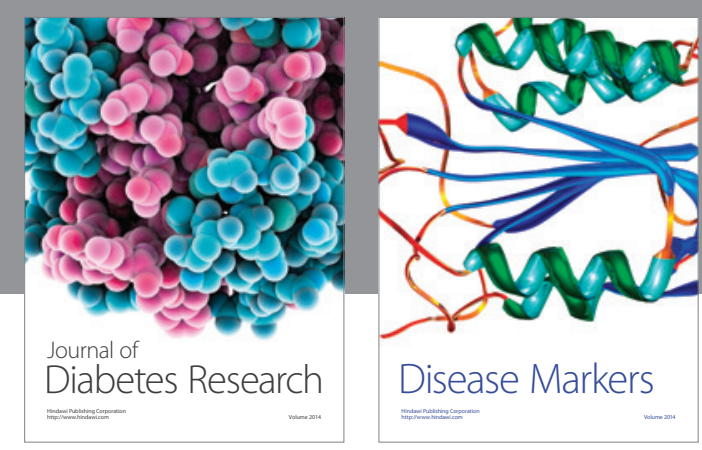

Disease Markers
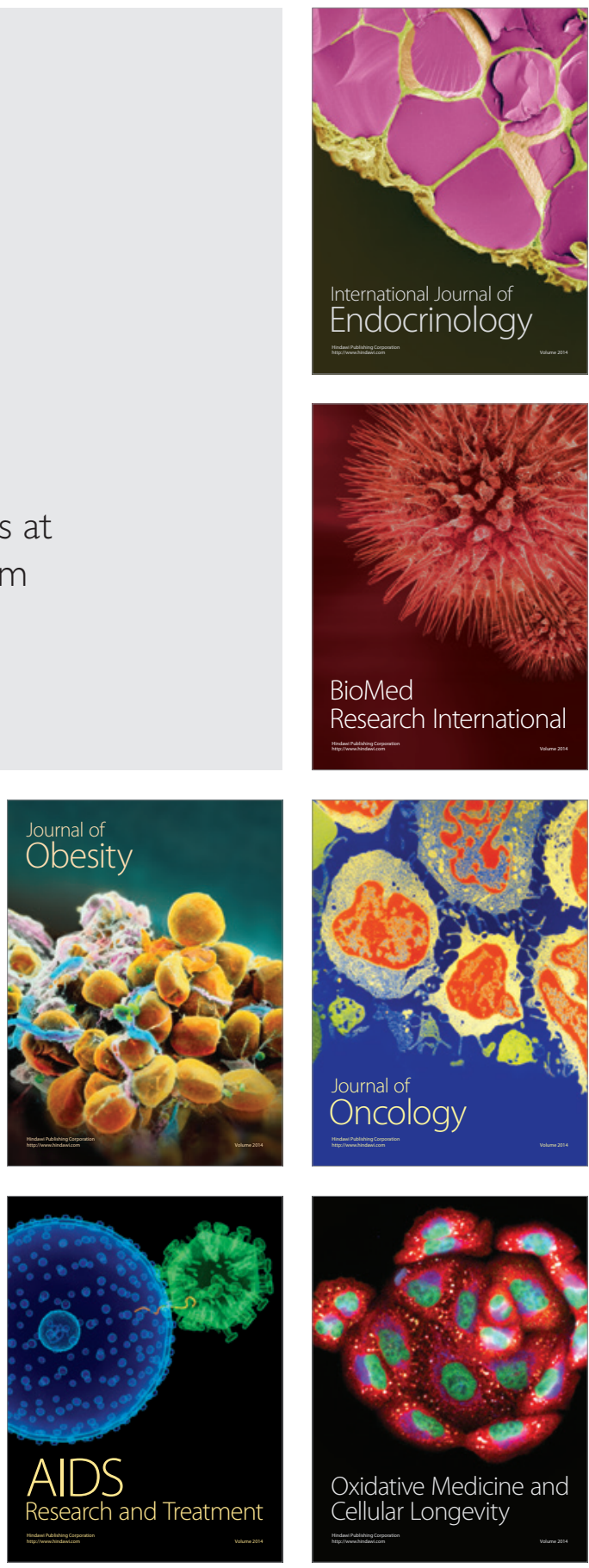